\title{
تصور مقترح الله من عمالة الأطفال في فلسطين وفقاً لبعض التبارب العربية
}

A proposed Scenario to Limit Child Labor in Palestine According to Some Arab Experiences

$$
\text { رحاب عارف السعدي }
$$


هدفت هذه الدراسة إلى تقديم تصور مقترح للحد من عمالة الأطفال في فلسطين وفقاً لبعض التجارب العربية، والتعرف على الهيئات المسؤلة عن تنفيذ التصور وآلية التنفيذ، وتم استخدام طريقة تحليل المضمون والطريقة المقارنة لعدد من الدراسات التي تمثل التجارب العربية في الحد من عمالة الاطفال وبلغت (22) دراسة أو تجربة، وتوصلت الدراسة الى النتائج الآتية: (أ) الهيئات التشريعية والتتفيذية والثريكة هي المسؤولة عن الحد من ظاهرة عمالة الأطفال؛ (ب) وزارة العمل، وزارة التربية والتعليم ووزارة التتمية الاجتماعية هي الهيئات التنفيذية للتصور المقترح؛ (ج) مؤسسات المجتمع المدني تمثل الهيئات

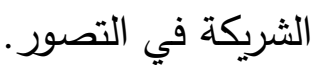
كلمات مفتاحية: تصور مقترح، عمالة الأطفال، فلسطين.

\section{Abstract:}

This study aimed to present a proposed perception to reduce child labor in Palestine according to some Arab experiences, and to identify the bodies responsible for implementing the perception and the implementation mechanism. The content analysis method and the comparative method was used for a number of studies that represent Arab experiences in reducing child labor. A total of (22) studies or experiments were reported, and this study reached the following results: (a) the legislative, executive and partner bodies are responsible for curbing the phenomenon of child labor; (b) the ministry of labor, the ministry of education and the ministry of social development are the executive bodies of the proposed scenario; (c) civil society institutions represent partner bodies in the visualization.

Keywords: perception, proposal, child labor, Palestine.

يعتبر الأطفال في المجتمعات نواة المستقبل التي تُنْى عليها الخطط والاستراتيجيات، فالمجتمعات التي لا تخطط للمستقبل من خلال بناء جيل قادر على إحداث نقلة نوعية في المجتمع، وتعزيز التتمية البشرية في كافة جوانبها الاقتصـادية والاجتماعية والثقافيـة، فإن مصيرها البقاء رهينـة لهـا هو سـائد ومعمول به من رجعية لا تتماشي ومتطلبات الحياة الكريمة والآمنة.

لذلك تعد مرحلة الطفولة من أهم المراحل العمريـة في حياة الفرد، فيها يتم تثكيل قدراته الجسمية التهية والعقلية والننسية، وإثباع حاجاته المختلفة، مما يساعد على تثكيل المعالم الرئيسية لثخصيته مستقبلاً،

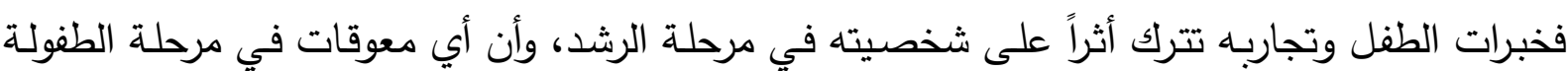
تؤثر على النمو السليم للطفل وصحته النفسية (مرعي، 2019). 
إنّ الاهتمام بالطفل ورعايته من مقومات النهوض بأي أمة فتية في سبيل الوصول إلى مستقبل أفضل، فالأطفال يشكلون جيل الغد والاهتمام بهم وإعدادهم لتحمل أعباء الحياة من أساسيات ومتطلبات التتمية الثاملة، ورعاية الطفولة لا تتفرد بها دولة دون أخرى سواء المتقدمة دنها أو النامية، وإن تفاوتت درجات الاهتمام بها بين الدول، لما أقرته الثرائع السماوية والاتفاقيات الدولية والتشريعات المحلية من حقوق بهدف حماية الطفل ورعايته في مرحلة يتم فيها تثكيل وبناء جسمه وإدراكه وشخصيته ليكون قادراً على لهى تحمل مسؤولياته تجاه مجتمعه. (الثامي، 2002). ونظراً لأهمية مرحلة الطفولة فإن هذا يتطلب المزيد من الرعاية والاهتمام للطفل كي ينشأ نثأة صحيحة، ولعل الدور الأكبر في هذه التتشئة يقع على عاتق الأسرة التي تعد من أهم مؤسسات التتشئة الاجتماعيـة التي تعنى بالطفل وتقوم على رعايته، وحمايته من الاستغلال والإهمال والعنف، وتوفير مستوى معيشي مناسب يفي بتلبية احتياجاته الانسانية، حتى لا تدفعه الظروف المعيشية للتوجه إلى سوق

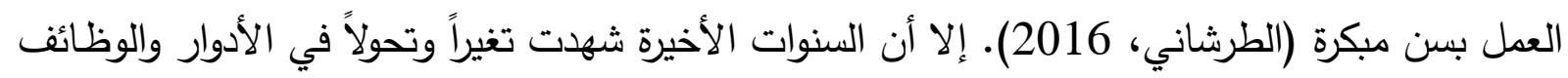
التي تقوم بها الأنساق الاجتماعية مثل الأسرة والمدرسة، حيث شهدت تغيراً كبيراً في الوظائف وتقسيم العمل بين الأفراد، مما أدى إلى اختلال التوازن وفقدان الدور الذي يقوم به كل نسق في الدجتمع، فالأسرة عندما تعجز عن تلبية متطلبات أطفالها فإن هذا يدفع بالأطفال إلى سوق العمل لمساعدة الأسرة وتلبية احتياجاته (بشير والناصر ، 2015).

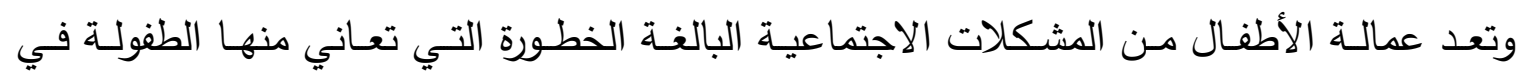
المجتمعات المتقدمة أو المتخلفة، وتتؤثر على نموها الاقتصـادي والاجتماعي (قحطان، 2007)، حيث يضطر الأطفال إلى اقتحام مجال العمل والتخلي عن طفولتهم سعياً وراء لقمة العيش، بالرغم من ظروف

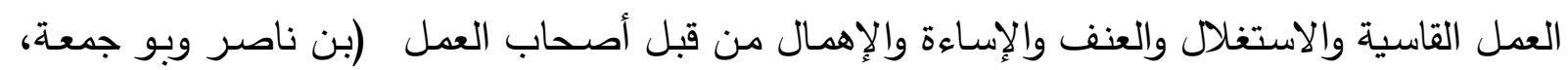

كذلك ما تعكسه هذه الظاهرة من آثار نفسية على حياة الطفل بشكل خاص، والأسرة والدجتمع بشكل عام ( الزعبوط، 2017).

كمـا تعد عمالـة الأطفال ظـاهرة عالميـة مـن حيث الانتشـار ضمن نسب متفاوتـة بحسب طبيعـة المجتمعات، ومدى إيلائها الاهتمام الكافي لهذه الثريحة المهمة من المجتمع، فمثلاً تتصدر قارة اسيا

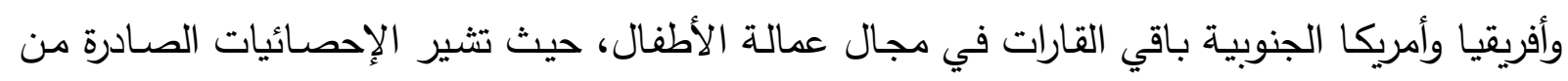
قبل منظمة العمل الدولية إلى أن عمل الاطفال على مستوى العالم عام 1996 يقدر ب 250 مليون 
طفل، وأن هذا الرقم تراجع في عام 2006 إلى 218 مليون طفل، نتيجة للعديد من المتغيرات، على الرغم من أن الامم المتحدة لم تقر بحقوق الطفل إلا في عام 1989، أي بعد مرور سنوات عدة على إنشاء المنظمـة الدولية، ورغم وجود العديد من الإعلانـات الخاصـة بحقوق الطفل، والتي كانت بمثابة بيانات للنوايا الحسنة، تعاني من مشكلة عدم إلزاميتها، إلا أن وجود الصكوك المختلفة لم يكن كافياً لحماية الطفل من شتى أنواع الانتهاكات الصارخة لحقوقه (ياقو، 2018).

مشكلة الدراسة وأسئلتها:

تقدر نسبة الأطفال في المجتمع الفلسطيني ما دون السن الثامنة عشرة 45\% من مجمل السكان في فلسطين البالغ عددهم 2.99 مليون نسمة في الضفة الغربية، وفي قطاع غزة يقدر عدد السكان بحوالي 1.99 مليون نسمة، ويمثل الأطفال ما نسبته 43\% في الضفة الغربية، و48\% في قطاع غزة، كما تثكل عمالة الأطفال في المجتمع الفلسطيني 3\% من إجمالي عدد الأطفال في الفئة العمرية( 1- 17)

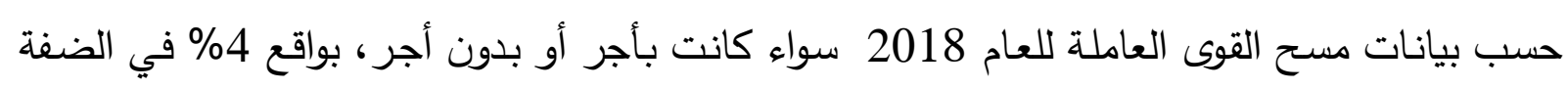

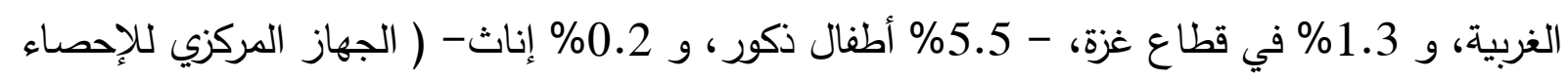
الفلسطيني، 2019).

ونتيجة لذلك تسبب عمالة الأطفال تأثيرات سلبية على الأطفال أنفسهم وعلى أسرهم وعلى المتمع بثكل عـام في كافـة المجـالات النفسية والاجتماعيـة والاقتصــادية والصـحية، وهذا مـا أكدتـهـ دراســة (العيسوي، 2017)، ودراسة (باعلوي، 2019)، ودراسة (الناصر، 2015)، ودراسة (الزعبوط، 2016)،

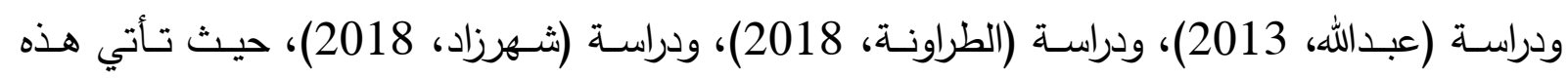
الدراسات لتصف التأثيرات والحلول المقترحة للحد من عمالة الأطفال في العديد من الدول العربية وهي:

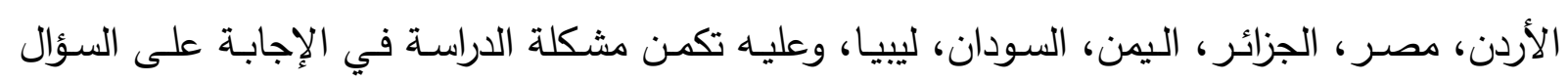
الرئيس الآتي: ما التصور المقترح للحد من عمالة الأطفال في فلسطين في ضوء، بعض التهن التجارب العربية؟

أسئلة الدراسة:

للإجابة على السؤال الرئيس تم تفريع الأسئلة الآتية:

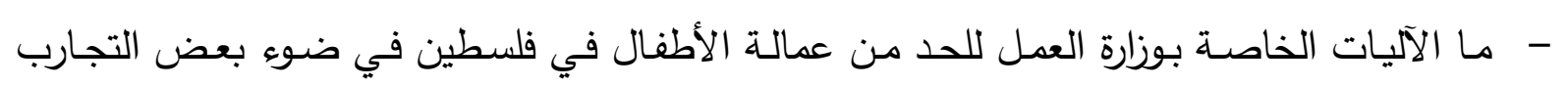
العربية؟ - ما الآليات الخاصة بوزارة التمية الاجتماعية للحد من عمالة الأطفال في فلسطين في ضوء بعض

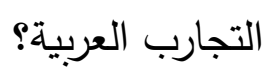


- - مـا الآليات الخاصـة بوزارة التربية والتعليم للحد من عمالة الأطفال في فلسطين في ضوء بعض

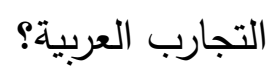

- ما الآليات الخاصة بالسلطة التشريعية للحد من عمالة الأطفال في فلسطين في ضوء بعض التجارب

العربية؟

- ما الآليات الخاصة بمؤسسات المجتمع المدني للحد من عمالة الأطفال في فلسطين في ضوء بعض

$$
\text { التجارب العربية؟ - n - n }
$$

أهداف الدراسة:

في ضوء مشكلة الدراسة يمكن تحديد أهداف الدراسة على النحو الآتي:

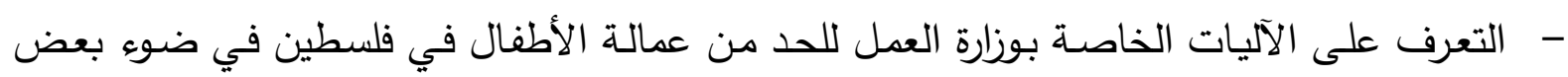

$$
\text { التجارب العربية. }
$$

- عديد الآليات الخاصـة بوزارة التتميـة الاجتماعية للحد من عمالـة الأطفال في فلسطين في ضوء

$$
\text { بعض التجارب العربية. }
$$

- - تبيان الآليات الخاصة بوزارة التربية والتعليم للحد من عمالة الأطفال في فلسطين في ضوء بعض

$$
\text { التجارب العربية. }
$$

- - توضيح الآليات الخاصة بالسلطة التشريعية للحد من عمالة الأطفال في فلسطين في ضوء بعض

$$
\text { التجارب العربية. }
$$

- - تحديد الآليات الخاصـة بمؤسسات المجتمع المدني للحد من عمالة الأطفال في فلسطين في ضوء

$$
\text { بعض التجارب العربية. }
$$

- - التعرف على مفهوم عمالة الأطفال، والعوامل المؤدية إليها، بالإضـافة للتأثيرات السلبية لعمالة

$$
\text { الأطفال. }
$$

أهمية الاراسة: - n

تتحدد الأهمية النظريـة للدراسة الحالية كونها تدرس موضوع عمالة الأطفال من منظور لم يتطرق

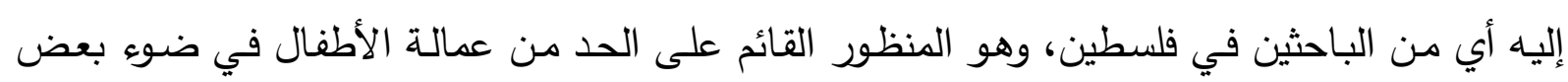
التجارب العربية والاستفادة من تلك التجارب، وبناء تصور للحد من تلك الظـاهرة، هذا ما يعزز قيمة

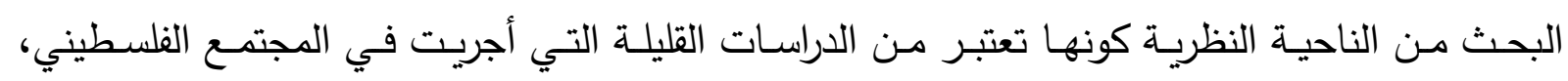
وتضمنت تصوراً للحد من عمالة الأطفال في المجتمع الفلسطيني، مما سيسهل على لـى الباحثين الآخرين 
الاستفادة من هذه الدراسة، كما ستغني الأدب النظري حول عمالة الأطفال، في حين تتمثل الأهمية التطبيقية في تقديم نتائج وتوصيات لأصحاب الاختصاص والجهات الرسمية في فلسطين وخصوصا وزارة التتمية الاجتماعية، والعمل والتربية والتعليم والأجهزة الأمنية، والسلطة التشريعية في التعرف على الآليات المناسبة للحد من عمالة الأطفال، وأن تعرف كل جهة رسمية الاليات التي تختص بها وتساهم من خلالها في الحد من عمالة الأطفال في المجتمع الفلسطيني من خلال التكامل مع كافة الجهات الرسمية. حدود الدراسة: الحد الموضوعي: تصور مقترح للحد من عمالة الأطفال في المجتمع الفلسطيني. الحد الزمني: أجريت الدراسة في الفترة الواقعة بين شهري 2 و7 من العام 2020. الحد المكاني: المجتمع الفلسطيني (الضفة الغربية وقطاع غزة). الحد البشري: يتمثل الحد البشري للدراسة بعمالة الأطفال.

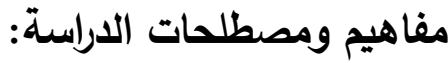
ترد في الدراسة بعض المفاهيم التي يجب تحديدها وتوضيحها وهي: عمالة الاطفال: إن مفهوم عمالة الأطفال يشير إلى الأنثطة التي يقوم بها الطفل سواء كانت بأجر أو بدون أجر لحسابه أو لحساب الآخرين ( الزعبوط، 2016). كما تتضمن عمالة الأطفال الأنشطة الخطرة Habib, Ziadee, Younes\& Harastani, ) في مجال الزراعة والتعدين والخدمة المنزلية والبناء .$(2020$

كما تعرف عمالة الأطفال بأنها " تثغيل الأطفال في المجالات الإنتاجية والخدمية بعيد عن إطار الأسرة مقابل أجر مادي، وقد يؤدي هذا إلى استغلال الطفل وتعريضـه لظروف عمل قاسية لا تراعي حقوقهـ التعليمية والصحية والاجتماعية والاقتصـادية والترفيهية، وتحرمـه من تطوير قدراته ويؤذي نموه البدني والعقلي والنفسي وسلوكه الأخلاقي والاجتماعي "( العيسوي، 2017).

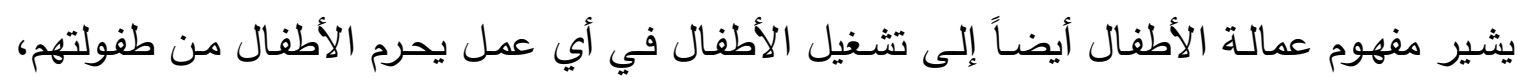

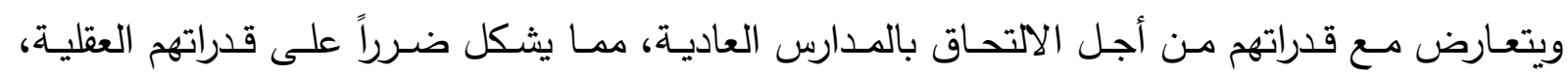
والجسمية، والاجتماعية، والمعنوية ( Khakshour, Abbasi, Seyedi \& Saeidi, 2015 ). كما يعرضهم لممارسات الاستغلال في العمل مثل التعرض للمواد الكيميائية والتغيب عن المدرسة، مما يؤثر بثكل كبير في نموهم ورفاهيتهم وصحتهم (Shendell et al., 2016). وتثير عمالة الأطفال أيضاً إلى كل عمل استغلالي يؤثر على صحة الطفل الجسمية والنفسية، أو يؤدي الى حرمانـه من التعليم 
والخدمات الأساسية ويعرضـه للمخاطر (الطراونـة والمعاني، 2018)، وهي أيضـا" مجموعة الأنثطة الهامشية التي لا ترتبط بالعملية الإنتاجية التي يمارسها الأطفال في الثوارع من أجل استمرار بقائهم أو

$$
\text { بقاء أسرهم" (موسى، 2009). }
$$

وتعرف منظمـة العمل الدولية عمالـة الأطفال بأنها " العمل الذي يؤذني سـلامة الطفل الجسدية والنفسية والذهنية " ، وأما منظمة الأمم المتحدة للطفولة(اليونسيف) فتعرفه بأنه" العمل الذي يستغل الطفل أو يعرضه للخطر وينتقص من صحة نموه الجسدي والنفسي والاجتماعي، وتمنع عنه التحصيل العلمي أو الوصول إلى الخدمات الأساسية"(ياقو وعلي، 2018). التصسور المقترح: فكرة مفصلة في إطار معين، تكون على شكل مخطط أو توجيهات مُمَرحلة، لتنفيذ برنـامج مـا، تدريبي أو تدريسي أو علاجي ... إلتخ، يضعهد - أي يقترحهـ - الباحث بنـاء على أسس معروفة في بناء البرامج في كل مجال، فالتصور بهذا المفهوم هو (مقترح) يرى الباحث أنه قد يحل مشكلة، وأنه يستحق التجريب. (الكريم، 2019). الإطار النظري لم تعرف الثعوب القديمة مفهوم عمالة الأطفال رغم تواجده كموضوع، فهو يعتبر من الدفاهيم المستحدثة والتي اختلفت الآراء حول أسبابه والعوامل المؤدية إليه (العيسوي، 2017). وتعد عمالـة الأطفال من أخطر المشكلات التي تواجههـا المجتمعات العربيـة، والتي تكثر فيها الحروب، والنزاعات والنقر وتدني مستوى الدخل والهجرات المتتالية، مما يستوجب التصدي لهذه المشكلة

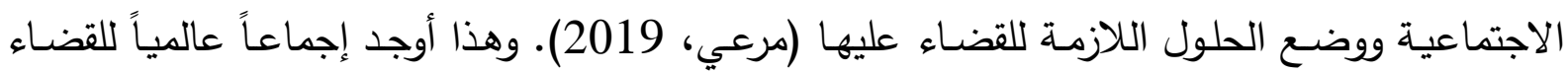

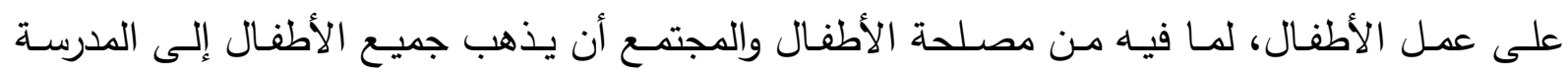
.(Webbink, Smits \&Jong, 2013 ) وقد طالبت العديد من التشريعات والقوانين بالقضاء على عمالة الأطفال، لأن الأطفال بهذه المرحلة

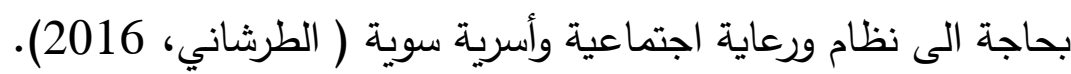
إلا أنه لا يمكن تصنيف جميع الأعمال التي يقوم بها الأطفال على أنها عمالة ويجب القئه القضاء عليها، حيث تعتبر مشاركة الأطفال والهراهقين في بعض الأعمال إيجابية، إذ لا تؤثر على صحتهم ونموهم الثخصي، ولا تتعارض مع دراستهم، مثل مساعدة الأسرة في بعض الأعمال خارج وقت المدرسة وفي العطلات الرسمية، فهذه الأنشطة تسهم في تنمية الأطفال ورفاهيتهم، وإكسابهم المهارات والخبرات، Khakshour, Abbasi, Seyedi \& وتساعد في إعدادهم ليكونوا أعضاء منتجين وفاعلين في المجتمع (Saeidi, 2015 . ولذلك يمكن أن يشارك الاطفال العاملين في أنشطة قد تكون مفيدة أو ضـارة، 
Edmonds \& Pavcnik, وهذا يعتمد على ظروف هذا النشاط، ومدى تأثيره على رفاهية الطفل(رد)

أما عن العمل الثاق للطفل Child Labour فهو يشير إلى العمل القاسي والمضني للطفل، والذي يهدف إلى كسب المال، وهذا النوع من العمل لا يمكن الطفل من ممارسة نشاطاته المدرسية، لأنه يستنفذ كل وقته بالعمـل ممـا يؤثر على طاقته، ويعرض صــته للمخـاطر الجسمية والنفسـية والاجتماعيـة ( زيتوني، 2017).

\section{الأسباب المؤدية إلى عمالة الاطفال:} تعددت آراء الباحثين حول أسباب عمالة الأطفال، إلا أنه كان هناك إجماع على جملة من الأسباب أولاً: أسباب ديموغرافية: الزيادة المضطردة في عدد السكان وزيادة نسبة المواليد وانخفاض عدد الوفيات، وذلك لاهتمام الدول بالجانب الصحي وبناء المستثفيات والمتابعة الطبية لأفراد المجتمع، والذي من شأنه يمكن أن يؤثر في حجم النشاط الاقتصادي للسكان، عدا عن الهجرات القسرية بسبب الحروب والصراعات الداخلية، والتي تزيد من نسبة القوى العاملة من الأطفال (زوزو وبن عيسى، 2016).

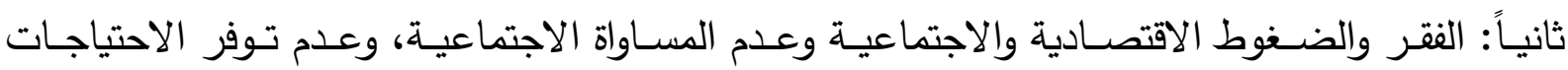
الاساسية للأسرة، مما يدفع بالأطفال للعمل للمساهمة في توفير نفقات المعيشة، وغالباً ما يكون هذا العمل استغلالياً للطفل يؤثر على نموه الجسمي والنفسي والعقلي (العيسوي، 2017). ثالثاً: العوامل التعليمية: عدم انتظام الطفل في المدرسة يكون دافعاً قوياً للانخراط في العمل بكافة أثكاله، خاصـة عندما يحصل على أجر لا يستطيع الحصول عليه وهو على مقاعد الدراسـة. وتعتبر منـاهج

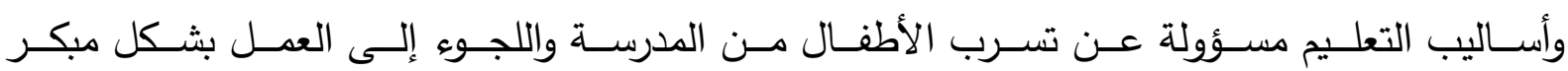

$$
\text { ( زوزو وبن عيسى، 2016). }
$$

كـلك تـنـي المستوى التعليمي والثقـافي للأسـرة بحيث لا تعنى بتعليم الطفـل ولا تـدرك أهميتهـ (ياقو وعلي، 2018)، كما أن صعوبة المناهج التعليمية، وقلة الأنثطة الثقافية والاجتماعية التي يمارسها الأطفال لتتمية مواهبهم، وافتقار المعلمين للأساليب والاستراتيجيات التدريسية المناسبة، كل ذلك يساعد الأطفال للتسرب من المدرسة والاتجاه نحو سوق العمل. رابعاً: العوامل الأسرية: ومنها التنكك الأسري، والخلافات الزوجية والثجارات العائلية بين الوالدين أو بين الوالدين والأبناء، مما يؤدي في معظم الحسالات إلى الطلاق والانفصـال، مما يؤثر على حياة الطفل 
واستقراره النفسي، وهذا يسهم في انفصال الطفل عن أسرته، والخروج إلى الثارع بدون أية ضوابط أو رعاية أسرية، للهروب من الجو العام داخل الأسرة، ويسعى للحصول على الدخل لتحقيق رغباته وقضاء

$$
\text { احتياجاته الأساسية. (بن زعزع، 2019). }
$$

خامساً: المشكلات الأسرية: وتتنج عن مرض أحد الوالدين أو ظروف طارئة ألمت بالأسرة مثل وفاة أحد

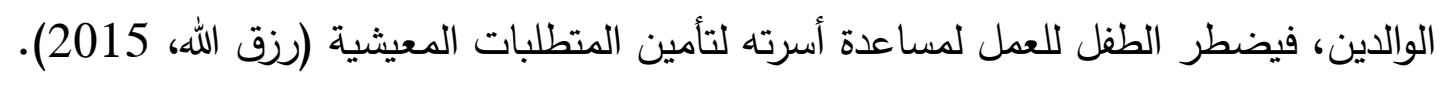

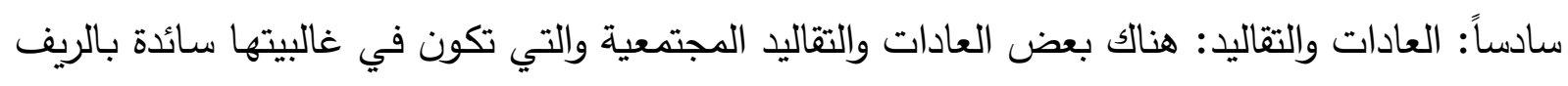

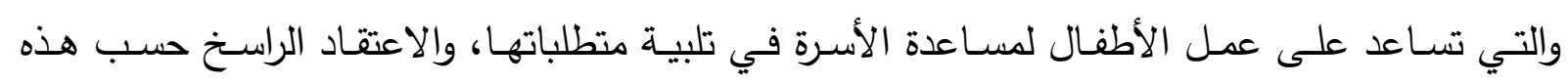

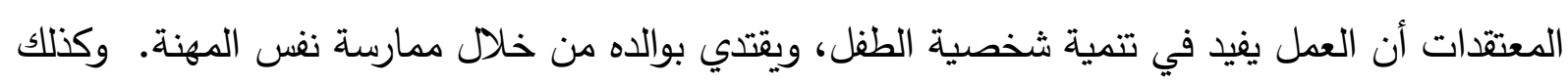
الاستغناء عن تعليم الفتاة بحجة أن مصيرها الزواج (العيسوي، 2017).

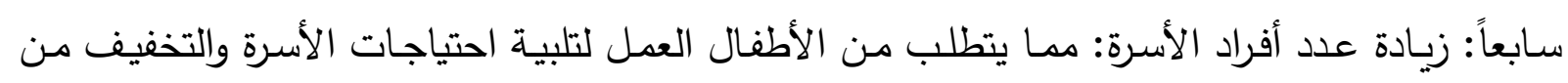
الأعباء الملقاة على كاهل الأسرة ( زوزو وبن عيسى، 2016). ثامناً: العوامل القانونية: لا يوجد تثريعات فعالة لتتفيذ الاتفاقيات في الدول العربية حول عمالة الأطفال وحقوقهم، وبالرغم من المصادقة على هذه الاتفاقيات إلا أنه لا توجد الآليات الكفيلة بتنفيذ تلك القوانين،

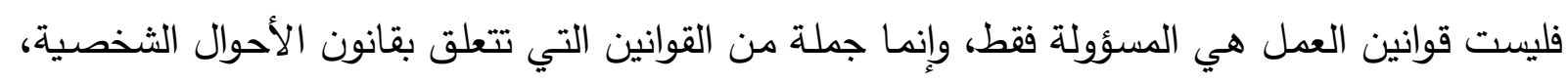

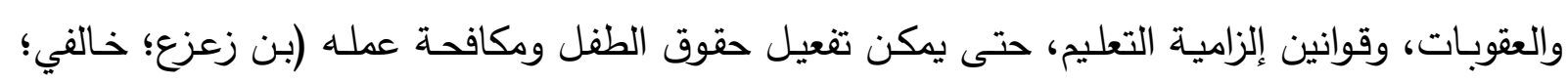
وخلفاوي، 2019). تأثيرات عمالة الأطفال: لعمالة الأطفال تأثيرات على الأطفال أنفسهم وعلى أسرهم وعلى المجتمع بشكل عام، ويمكن حصر تلك التأثيرات في ما يأتي: أولاً: التأثيرات النفسية: تؤثر عمالتة الأطفال على الصحة النفسية للأطفال ممـا يعرضهم للاضطراب النفسي (Amon, Buchanan, Cohen \& Kippenberg, 2012) ، كما تؤثر أيضاً على النمو العاطفي والمعرفي، والسلوكي لدى الأطفال، مما يؤدي إلى شعورهم بالدونية وعدم تقديرهم لذواتهم، مدا

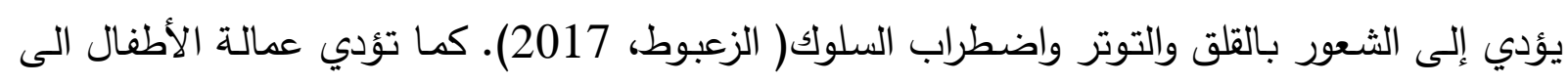
عدم قدرة الأطفال على التكيف الذاتي والاجتماعي في مجال العمل وعدم الإحساس بالاستقلالية، كما

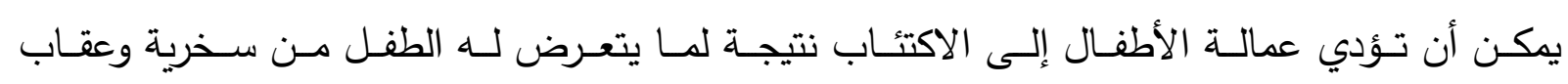
( رزق الله، 2015). 
ثانياً: التأثيرات الجسدية: وتتمثل هذه الإساءة بالإيذاء الجسدي مثل الضرب، والحرق، والحبس، وتعتبر هذا الإساءة الأكثر شيوعاً بسبب سهولة اكتثافها وملاحظة أعراضها الظاهرية، وتتضمن الإساءة للطفل أيضاً الإساءة الجنسية وتتمثل في استخدام الأطفال العاملين في أنثطة للاستغلال الجنسي للأطفال، مثل التحرش والاعتداء الجنسي عليهم (زوزو وبن عيسى، 2017). ثالثاً: التأثيرات الصحية: عمالة الأطفال في سن مبكرة لها أثر سلبي على النمو الجسمي، فقد يصـاب النداب الطفل ببعض الأمراض أو الإصـابات الجسدية المزمنة والتي يصعب علاجها مثل التشوهات العضلية وغيرها من التشوهات والتي تؤثر على معدل النمو وتوازن الأجهزة المختلفة (العيسوي، 2018). كما يترك العمل آثار صحية خطرة على الأطفال وخاصـة الأطفال العاملين في المجال الزراعي من حيث التعرض للمبيدات والمواد الكيميائية، أو العمل في الوش الته والمصانع والتعرض للإصـابة أو الموت بسبب (Amon, Buchanan, Cohen \& Kippenberg, 2012 ). (الآليات الثقيلة (جاد، 2019) رابعـاً: التأثيرات الاجتماعيـة: وتتمثل باضطراب العلاقـة الاجتماعيـة بين الطفل وأسرته، ويغلب لديـه الإحساس بسيطرة الآخرين عليه، وأن يكون تابعاً، نظراً لأساليب العنف والسيطرة التي تمارس عليه، كما أن القيم التي يكتسبها أثناء العمل قد تكون إيجابية أو سلبية وبالتالي تكون جزءاً من مكونات شخصيته

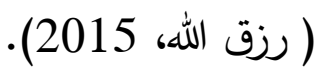

خامساً: التأثيرات الثقافية: تؤثر عمالة الأطفال على التطور الثقافي والأخلاقي للطفل العامل من حيث قدرته على الكتابة والقراءة والتحصيل الدراسي وقدراته المعرفية، مما يؤثر سلباً في تطوره المعرفي، وعدم

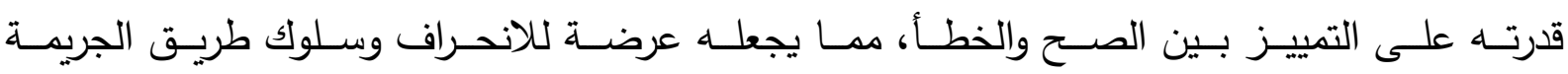

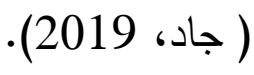

سادساً: تأثثرات عمالة الأطفال على المجتمع: إن عمالة الأطفال تؤدي إلى تدمير البناء الاجتماعي

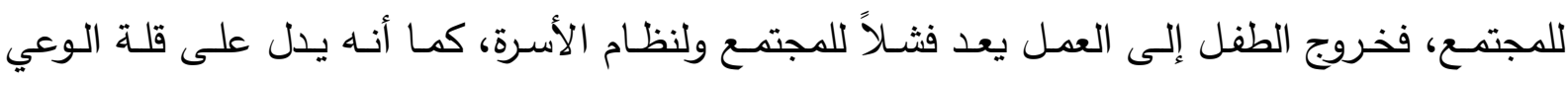

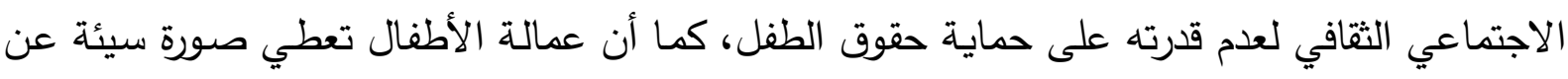
المجتمع وحضارته وعمرانه (العيسوي، 2018). أشكال عمالة الأطفال:

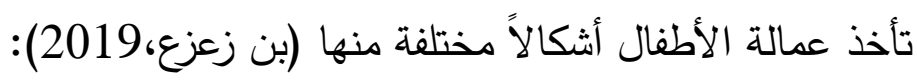
أولا: الأعمال الصناعية: وتشمل هذه الفئة الأعمال التي يقوم بها التعاع، الطفل في المناجم أو المحاجر ، وكل

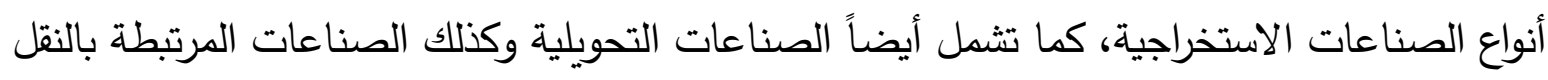
والسكك الحديدية، أو العمل في المصانح، أو أماكن تصليح السيارات. 
ثانيا: العمل في الأسواق: فالأطفال قد يبيعون أغراض عينية أو مواد ما، مثلا بيع أدوات الزينة أو بعض فل الاطعمة السريعة، كما قد يكون عملهم في الأسواق تحت سلطة مجل تجاري موجود في السوق، فكل هذه الحالات تعرض الطفل للخطر . ثالثا: العمل في الثـوارع: تشمل هذه الأعمال مجموعـة من الأعمال الهامشية كبيع بعض المنتجات

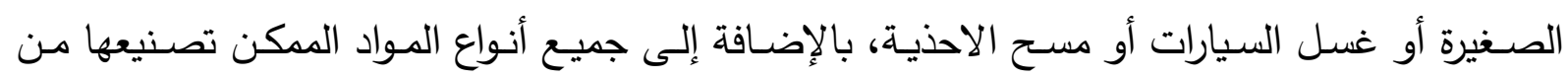
المنازل والقمامات لإعادة بيعها. رابعا: العمل في المنازل: هنالك من ينظر لهذا الثكل من عمالة الأطفال من منظور إيجابي، نظراً لأنه في محيط عائلي، فقد يكتسب من خـلال هذا النوع الخبرات، وتعزيز ثقته بنفسه وقدرته على مواجهة تحديات الحياة مستقبلاً، ويعد ذلك صحيحاً إذا ما اقتصر قيام الطفل على بعض الأعمال البسيطة التي لا تثكل خطراً على صحته. عمالة الأطفال في الاتفاقيات الدولية: إن الاهتمام برعاية الأطفال موجود منذ بداية الإنسانية، وقد تزايد الاهتمام بالطفولة وأخذ بعداً عالمياً في عام 1924، حيث أقرت الهيئة العامـة لعصبة الأمم إعلان حقوق الطفل، ونتيجة الحرب العالميـة الثانية فقدت هذه الوثيقة قيمتها، لكن مع تأسيس هيئة الأمم عام 1946 أوصي بإعادة النظر في هذا الإعلان، وبصدور إعلان حقوق الإنسان عام 1948 عبرت فيه كل الدول عن اهتمامها بالطفل، وعلى الرغم من إشارة هذا الإعلان بشكل صريح إلى حقوق الطفل وحريته إلا أن ذلك لا يعد كافياً ولا يغطي

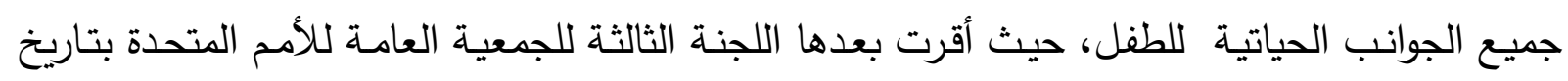
1959/11/20 (الإعلان العالمي لحقوق الطفل)، وأصبح بعدها الإعلان من أهم الوثائق في الحياة الإنسانية، تبعها بعد ذلك قيام الأمم بإنشاء منظمة متخصصـة في مجال الطفولة في عام 1964 هي

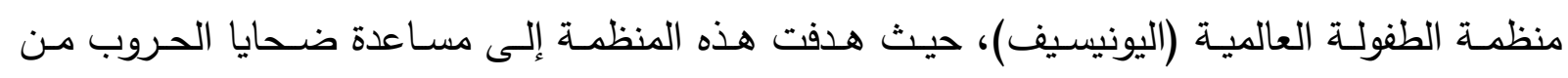
الأطفال، بالإضافة إلى الصحة والتغذية والتربية والتعليم، وتوالت بعدها العديد من الاتفاقيات التي تختص هـ التصاله

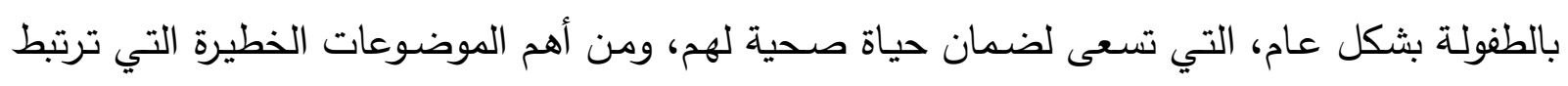

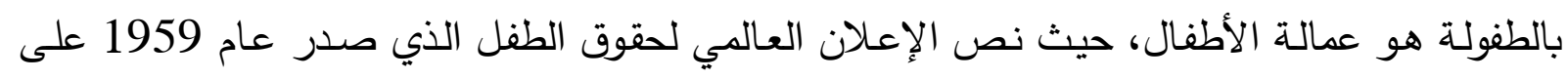

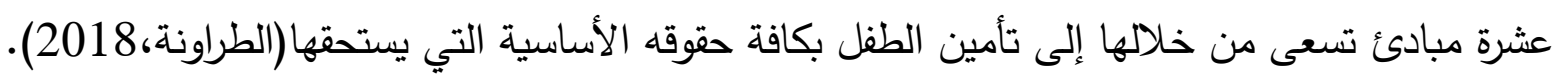

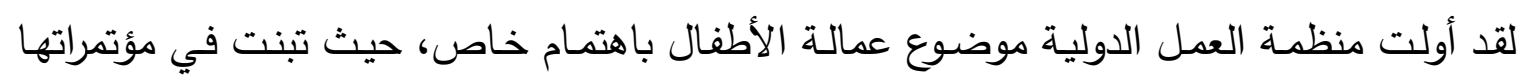
(138) اتفاقية عام 1976، اشتملت على العديد من الموضوعات المرتبطة بعمل الأطفال، وتتميز هذه 
تصور مقترح للدد من عمالة الأطفال في فلسطين ... رحاب السعدي وعصام الأطرش

الاتفاقية بالثمول، حيث حددت الحد الأدنى للعمل بثكل عام، والحد الأدنى للأعمال الخطيرة، ومن ثم بعد ذلك جاءت اتفاقية حقوق الطفل عام 1989 التي تمثل الإطـار العام لتتمية قدرات الطفل، حيث نصت المادة 32 من اتفاقية حقوق الطفل على تتظيم عمل الطفل، ثم اتفاقية رقم 182 لسنة 1999 بشأن حظر أسوأ أشكال عملهم بجميع أشكال الرق وبيع الأطفال والاتجار بهم، والعمل القسري، أو استخدام الطفل لأغراض الدعارة أو أنثطة غير مشروعة كالمخدرات، بالإضـافة إلى الأعمال التي تئدي

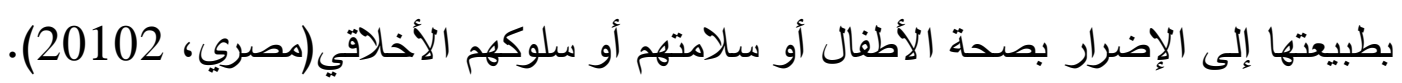

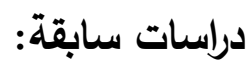

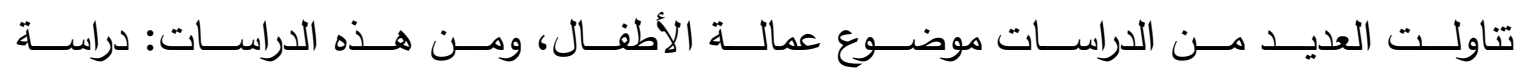
(Khatab, Raheem, Sartorius \& smail, 2019)، وقد هدفت إلى معرفة مدى انتشار عمالة الأطفال وعوامل الخطر والعنف ضد الأطفال في مصر باستخدام النمذجة المكانية الجغرافية. أظهرت

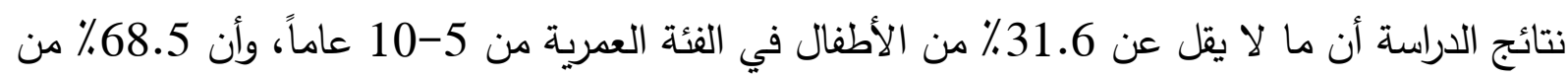

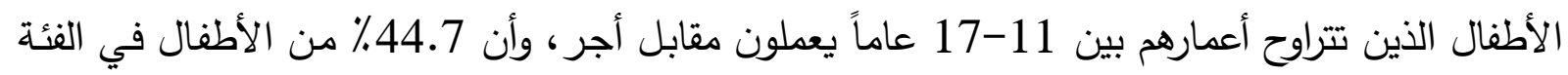
العمرية من 5-10 عاماً، كانوا يعملون في أعمال خطرة. وكثفت نتائج الدراسة أيضاً عن وجود تأثير هام للعوامل الاجتماعية والديموغرافية والاقتصادية على عمل الأطفال والعنف ضد الأطفال في مصر . إن الفقر والإهمال وانعدام الرعايـة المناسبة وتعرض الأطفال لمختلف درجات العنف تعد من العوامل الرئيسية لعمل الأطفال بعلم الدولة. يثير التأثير الدكاني إلى الحاجة إلى إيلاء مزيد من الاهتمام لبعض

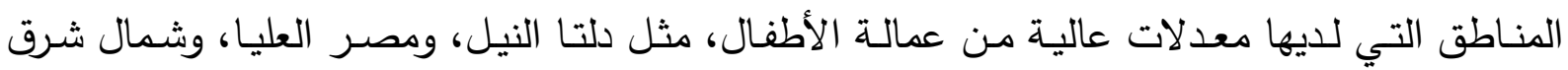

وهدفت دراسـة الطراونــة والدعاني (2018) إلى تقيـيم السياسـات الاجتماعيـة لعمالـة الأطفال في

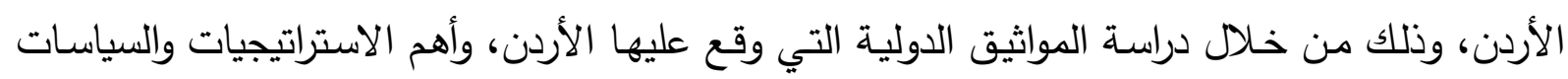
والخطط الوطنية العاملة في مجال عمالة الأطفال، بالإضـافة إلى آلية تطبيق هذه الاستراتيجيات من خلال البرامج التي تم تطبيقها على أرض الواقع. ومن أجل تحقيق هذا الغرض تم استخدام المنهج الكيفي لتكوين فهم أعمق للسياسات الاجتماعية والاستراتيجيات الوطنية من ناحية التصميم، وآلية تطبيقها وتحليل

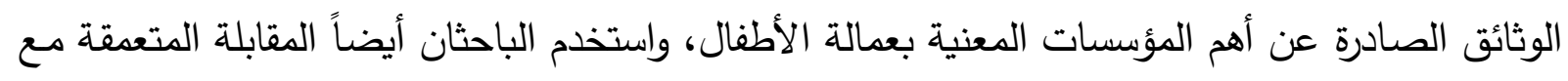
عينة من الخبراء في مجال عمالة الأطفال والعاملين في مكافحتها. وأظهرت نتائج الدراسة أنه على الرغم من التزام الأردن بالتوقيع على الاتفاقيات الدولية المتعلقة بعمالة 
الأطفال إلا أن هناك ضعفاً في تصميم السياسات الخاصة بمكافحة عمالة الأطفال وتتفيذها، وضعف في التتسيق بين الوزارات والمؤسسات المعنية في هذا المجال مما يؤدي إلى تقديم خدمات غير متكاملة للأطفال العاملين وأسرهم، إضافة إلى عدم تطوير التشريعات والسياسات أو تعديلها بالثكل المناسب للحد من تلك الظاهرة. في حين هدفت دراسة (Roggero, Mangiaterra, Bustreo \& Rosati, 2018) إلى التعرف على تأثير عمل الأطفال على صحتهم، تكونت عينة الدراسة من الأطفال العاملين في البلاد النامية والتي تتراوح أعمارهم بين( 10-14) سنة. أظهرت نتائج الدراسة أن عمالة الأطفال مرتبطة بشكل كبير بوفيات المراهقين الناتج عن الأمراض المعدية، وانخفاض المستوى المعيشي والذي هو دون الحد الأدنى.

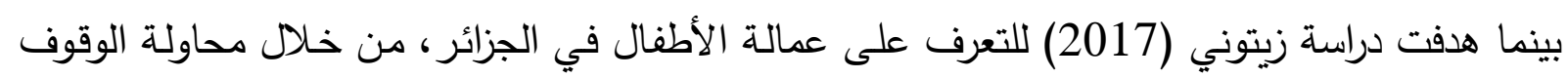
على العوامل المساهمة في استفحال هذه الظاهرة. أظهرت نتائج الدراسة أن الدافع الأول وراء عمل هؤلاء

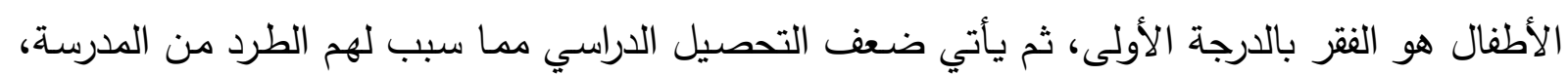

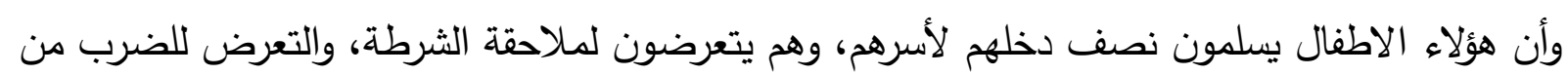
الأثخاص الأكبر سناً. وأظهرت نتائج الدراسة أيضاً انتشار العديد من القيم السيئة مثل التخخين.

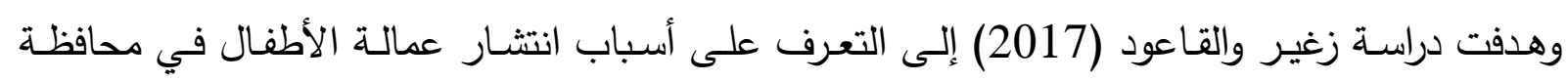
الهفرق من وجهة نظر معلمي الدراسات الاجتماعية. تكونت عينة الدراسة من (143) معلماً ومعلمة تم اختيارهم بالطريقة العشوائية العنقودية الطبقية، استخدم الباحثان المنهج الوصفي المسحي. أظهرت نتائج

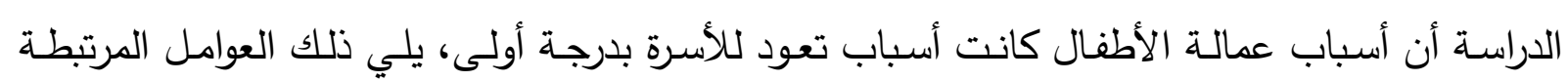

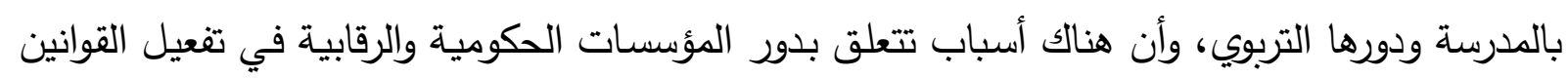
والتشريعات الموجهة لحماية الطفل. بينما أجرى بن ناصر وبو جمعة (2017) دراسة هدفت إلى بيان خطورة عمالة الأطفال في الجزائر

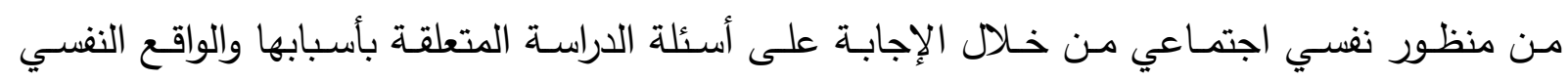

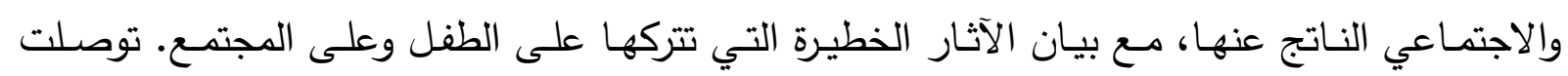

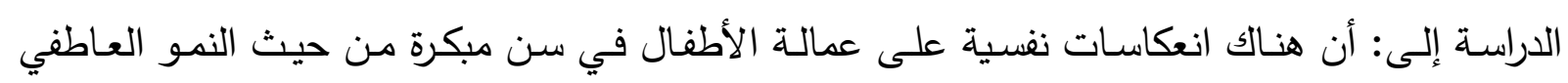

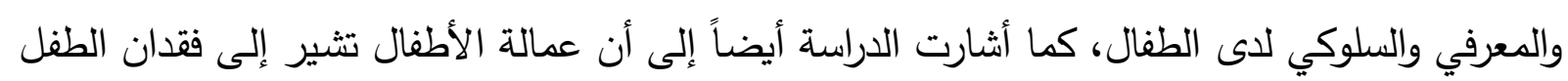
لفرص التعليم والتسرب من المدرسة والتعرض للعنف، واكتساب العادات والسلوكيات السيئة، والتعرض للاستغلال الاقتصادي والجنسي. 
تصور مقترح للدد من عمالة الأطفال في فلسطين ... رحاب السعدي وعصام الأطرش

وأجرى كل من (Zafar, Sarwar \& Haider, 2016) دراسة حاولت تسليط الضوء على الأسباب الاجتماعية والاقتصادية والسياسية لعمالة الاطفال في الباكستان. خلصت الدراسة إلى وجود العديد من العوامل الاجتماعية والاقتصادية المسؤولة عن عمالة الأطفال أهمها: الفقر ، الوضع الاقتصادي للوالدين، عدد أفراد العائلة الكبير، عوامل ثقافية، الهجرة من الريف الى الحضر، فثل التعليم وعدم الثقة فيه، وقلة المراقبة في تطبيق القوانين. وقام كل من (Diane, Putnick \& Bornstien, 2015) بدراسة هدفت الى استكثاف العلاقة بين عهل الأطفال خـارج المنزل والعهل العائلي والأعهـال المنزليـة والالتحـاق بالمدارس في الدول الناميـة والمتوسطة الدخل. أظهرت نتائج الدراسة وجود علاقات سلبية كبيرة بين جميع أشكال عمل الأطفال والتسجيل في المدارس. وهذا يعتمد على قرب المدرسة والجودة والتكلفة والمسافة إلى المدرسة، والمعرفة الأبوية عن المدرسة، والقدرة المعرفية للأطفال. وقام الطواشي (2015) بدراسة هدفت إلى التعرف على واقع عمل الأطفال في قطاع غزة، وتوضيح أثر هذا الواقع على المستقبل المهني للأجيال القادمة، مع دراسة الجوانب المتعلقة بهذه الظاهرة وتحليلها من حيث الأسباب والآثار السلبية الناتجة عنها. تكونت عينة الدراسة من (161) موظف يعملون في مجال حماية الطفل في المؤسسات الحكومية وغير الحكومية والمؤسسات الدولية. توصلت الدراسة إلى أن عمالة الأطفال هي مشكلة لها وجود حقيقي في المجتمع الفلسطيني، ووجود أثر سلبي واضـح لعمالة الأطفال على المستقبل المهني للأجيال القادمة في قطاع غزة. وأشارت النتائج أيضاً إلى وجود أثر سلبي لعمالة الأطفال على تدني مستوى التطور المعرفي للأطفال العاملين، وأن هناك أسباب مختلفة تقف وراء عمالة الأطفال، كما أشارت النتائج إلى وجود أثر سلبي على تدني الخبرة الحياتية والمهنية للطفل العامل، وتنني فرص توفر وظائف مستقبلية أفضل لهؤلاء الأطفال. وأجرى كل من (Mansour, Al-Gamal, sultan,Matrouk\& Al-Nawaisieh, 2013) دراسة هدفت إلى استكثاف التأثير الصحي النفسي والجسدي لعمل الأطفال في الأردن ومقارنته بين الأطفال العاملين وغير العاملين في المدارس والمواقع الصناعية. تكونت عينة الدرسة من ( 4008) طالب من طلاب المدارس الصناعية. أظهرت نتائج الدراسة أن الأطفال الذين يعملون يعانون من مشاكل صحية وجسدية ونفسية مختلفة، مثل مشاكل البرد والانفلونزا والسمع والبصر ، إضافة إلى الشككلات النفسية مثل: الثـعور بالوحدة، والثـعور بالاكتئاب وارتفاع مستوى الغضب وتدخين السجائر واستخدام المخدرات. وقامت كاظم (2011) بدراسة هدفت إلى معرفة أسباب انتشار عمالة الأطفال من وجهة النظر التربوية 
والنفسية والاجتماعية، ومعرفة أسبابها من وجهة نظر الأطفال العاملين أنفسه. أظهرت نتائج الدراسة أن انخفاض دخل الأسرة للطفل حاز أعلى درجـة، في حين حاز عقاب الأهل للطفل على أقل درجة. وأظهرت نتائج الدراسة أن عمالة الأطفال تتنشر بين الذكور أكثر من الإناث، وأعلى نسبة تسرب كانت بين الذكور في الصف الخامس. وأجـرى محافظــة (2011) دراســة هـدفت إلـى التعـرف إلـى الخصــائص الاجتماعيـة والتعليميـة والاقتصادية والصحية للأطفال العاملين في الأردن، والتعرف إلى الأسباب التي دفعت بهؤلاء الأطفال

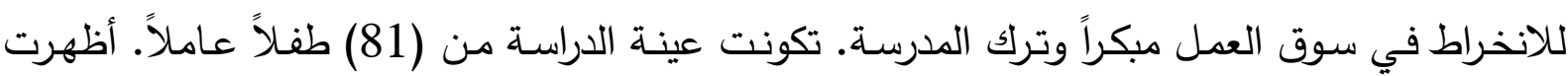
نتائج الدراسـة أن أهم أسباب عمالـة الأطفال هـي: مسـاعدة الأسـرة ماديـاً، ضـعف مستوى التحصيل الدراسي، سوء معاملة المدرسين والإداريين، ضغط الأسرة، الرغبة في تعلم مهنة. وقام أبو زايد (2010) بدراسة هدفت إلى التعرف على علاقة الرضا عن العمل بالتوافق النفسي لاى الأطفال العاملين في المحافظة الوسطى. تكونت عينـة الدراسة من (80) طفلاً تتراوح أعمارهم ما بين (15-15 سنة في منطقة دير البلح، ومنطقة الزوايدة في الدحافظة الوسطى بقطاع غزة. أظهرت نتائج الدراسة أنه لا يوجد علاقة ذات دلالة إحصائية في مجالات الرضا عن العمل والتوافق النفسي. وتتفق هذه الدراسة مع الدراسات السابقة في الدجالات التالية: - تناولت هذه الدراسة كسائر الدراسات السابقة مفهوم عمالة الأطفال، كما بين الأسباب المؤدية إلى عمالة الأطفال والتأثيرات السلبية لعمالة الأطفال. - - اتفقت هذه الدراسة مـع الدراسات السابقة، بأن عمالة الاطفال ظاهرة اجتماعية أثرت بثكل سلبي على جميع المجتمعات البشرية باختلاف بسيط في درجة انتشارها.

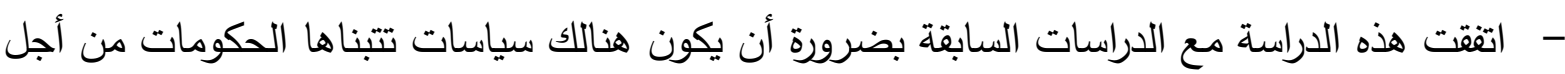

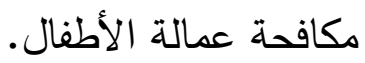

$$
\text { واستفادت الدراسة الحالية من الدراسات السابقة من خلال ما يلي: }
$$
- - الإلمام بالمعلومات حول عمالة الأطفال، والاستفادة منها في إعداد الإطار النظري ومشكلة الدراسة. - الاستفادة من نتائج الدراسات السابقة في مقارنتها بنتائج الدراسة الحالية. - - الاستفادة من الجانب النظري للدراسات السابقة من خلال الاطلاع على تجارب الباحثين السابقين والبدء من النقطة التي انتهوا بها. - - الاستفادة من الدراسات السابقة في إعداد اسئلة الدراسة الحالية. 
وقد تميزت الدراسة الحالية عن الدراسات السابقة في المجالات التالية: - - استخدم في هذه الدراسة منهج تحليل المضمون، بخلاف الدراسات السابقة التي استخدم فيها المنهج الوصفي التحليلي. - - يتميز مجتمع الدراسـة بكونه تمثل بالدراسـات السابقة التي اشتملت على العديد من التجارب العربية في مجال مكافحة عمالة الأطفال. - قامت هذه الدراسـة ببناء تصور مقترح للحد من عمالة الأطفال على خلاف الدراسات السابقة التي اقتصرت على تحديد الأسباب وتأثيرات عمالة الأطفال. - - مصادر البيانات في الدراسة الحالية يعتمد على الدراسات السابقة التي تمثل حصيلة التجارب العربية في مكافحة عمالة الأطفال. الإجراءات المنهجية للدراسة منهج الاراسة:

اعتمدت الدراسة طريقة تحليل المضمون لتحليل بعض التجارب العربية في مكافحة عمالة الأطفال، واعتمدت الطريقـة المقارنـة لإجراء مقارنـة ببعض التجـارب العربيـة أيضــاً، وذلك من أجل الوصـول إلى لى تصور كامل يتضمن الآليات المناسبة لمكافحة عمالة الأطفال في فلسطين. مصادر البيانات:

اعتمدت على مصادر غير ميدانية (جاهزة) للحصول على معلومات وبيانات تم الحصول عليها من الدراسات والكتب والتقارير التي أجريت في العديد من الدول العربية والتي تتعلق بمكافحة عمالة الأطفال.

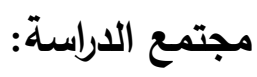
تضمن مجتمع الدراسة جميع الدراسات في الدول العربية في مجال مكافحة عمالة الأطفال على حد علم الباحثين. عينة الدراسة: تكونت عينـة الدراسـة مـن (22) دراسـة تشير إلى خمس تجـارب عربيـة في مجال مكافحـة عمالة الأطفال وهي: مصر ، الأردن، الجزائر، ليبيا، اليمن، السودان. طرق تحليل البيانات: اعتمدت الدراسـة أسلوب التكرار في تحليل البيانـات، التي تم الحصـول عليها من الدراسـات التي تمـت الإشارة إليها. 
عرض نتائج الدراسة ومناقثتها:

السؤال الرئيس: مـا التصـور المقترح للحد من عمالـة الأطفال في فلسطين في ضوو بعض التجارب

العربية؟

في ضوء ما تم عرضده، توصل الباحثان إلى تصور مقترح لمكافحة عمالة الأطفال في فلسطين، وفق

النقاط التالية:

أولاً: الهيئات المسؤولة: هنالك ثلاث هيئات مسؤولة عن مكافحة عمالة الأطفال وهي: 1-الهيئات التشريعية: تمثل السلطة التنفيذية الهيئة التشريعية في ظل الظروف غير العادية التي تمر بها فلسطين، وفي ظل الظروف العادية يعتبر المجلس التشريعي. 2- الكيئات التنفيذية: تتمثل بوزارة العمل، ووزارة التربية والتعليم ووزارة التتمية الاجتماعية. 3- الهيئات الثريكة: تتمثل في مؤسسات المجتمع المدني ووسائل الإعلام المختلفة. ثانياً: آلية التنفيذ: يقوم تتفيذ التصور المقترح بمكافحة عمالة الأطفال وفق ما يلي: 1-تقوم الهيئات التشريعية برسم السياسات التشريعية المناسبة لمكافحة عمالة الأطفال، وذلك من خلال النقاط التالية:

- إقرار التشريعات الخاصة بحماية الطفل بما ينسجم مع الاتفاقيات الدولية. - إجراء التعديلات المناسبة على القوانين السـارية لحمايـة الطفل بهـا يتوافق مـع الظروف الاجتماعية والاقتصادية.

- تثديد العقوبات على أصحاب العمل المشغلين للأطفال. - تحديد سن العمل للأطفال بما لا يقل عن 16 سنة. - تحديد الأعمال الصعبة والخطرة التي يحظر على الأحداث العمل فيها. 2-تقوم الهيئات التنفيذية بمتابعة تتفيذ التثريعات والقوانين الخاصة بحماية الطفل، وفق النقاط التالية: - تقوم وزارة العمل بزيـادة أعداد المفتشين في وزارة العمل لمتابعـة الأطفال العاملين في سوق العمل،

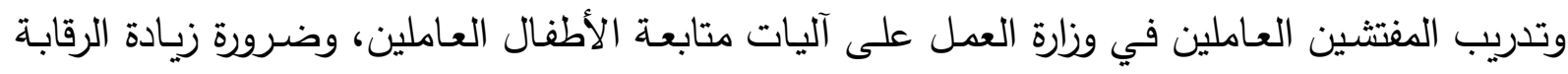
على الأماكن التي يعمل فيها الأطفال. - تقوم وزارة التتمية الاجتماعية في زيادة مرشدي حماية الطفولة العاملين في وزارة التتمية الاجتماعية،

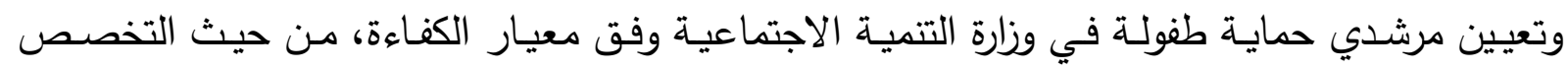

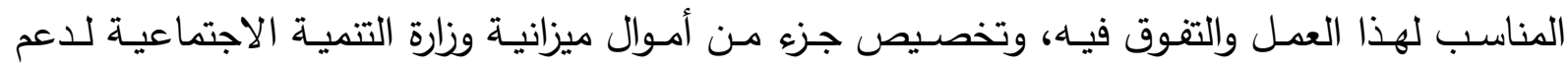
الأطفال المهددين بالخطر . 
- تقوم وزارة التربية والتعليم بزيادة عدد الددراس والصفوف الدراسية، وتحسين البيئة المدرسية، لاستيعاب الأطفال وفق ظروف ومناخ علمي وتربوي، ووضع الحلول المناسبة لظاهرة التسرب المدرسي، وتعيين أخصائيين اجتماعيين في المدارس.

3- الهيئات الثريكة: تقوم مؤسسات المجتمع المدني بالتعاون والتنسيق مع الهيئات التنفيذية ذات العلاقة بحماية الطفل، وتقديم الدعم المادي والمعنوي للأطفال المهددين بالخطر من خلالهم. وللإجابة على الأسئلة الفرعية على النحو التالي:

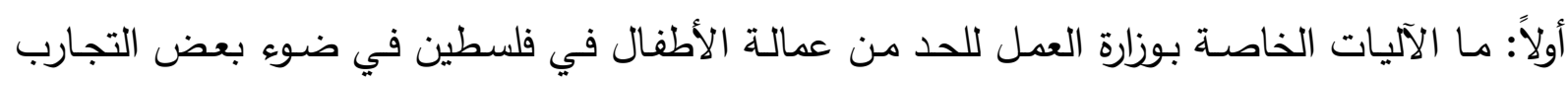
العربية؟ أجمعت معظم الدراسـات السـابقة إلى ضـرورة توفير بيئـة صـية، وآمنـة للأطفال العـاملين والحد من استغلالهم في المهن الخطيرة والثاقة والمضرة بصحتهم، وضرورة مراقبة المنشآت والأماكن التي يستخدم الأطفال فيها خارج إطار القانون. كما أجمعت معظم الدراسات السابقة إلى ضرورة زيادة أعداد المفتثين في وزارة العمل لمتابعة الأطفال العاملين في سوق العمل، وضرورة تدريب المفتشين العاملين في وزارة العمل على آليات متابعة الأطفال العاملين، وضرورة زيادة الرقابة على الأماكن التي يعمل فيها الأطفال. وقد اتجهت بعض الدراسات السابقة إلى ضرورة تتظيم ساعات العمل في الحالات التي يسمح بها المشرع بعمل الأطفال، بحيث يجب أن لا تزيد ساعات العمل عن سبع ساعات في اليوم، كما يجب أن تتخلل ساعات العمل اليومية فترة للراحة لا تقل مدتها عن ساعة، وأن لا يعمل الحدث عمل متواصل أكثر من أربع ساعات، وحظر تثغيل الأحداث ساعات عمل إضافية أو في أعمال ليلية، وحظر تشغيل الأحداث في الأعمال الخطرة، واعتبار السـاعات التي يقضيها الحدث في التدريب من سـاعات العمل اليومية، وحظر تشغيل الأحداث في أوقات الراحة الأسبوعية والعطل الرسمية والإجازات، وتوفير بيئة عمل صحية وآمنة، وحظر تثغيل الأطفال في المناطق النائية والبعيدة عن العمران.

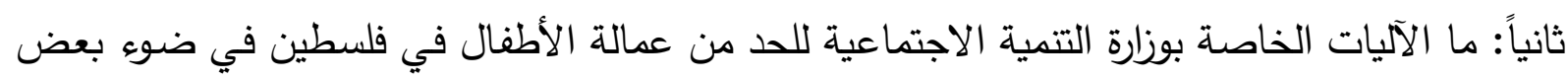
التجارب العربية؟ أجمعت معظم الدراسات السابقة على ضرورة زيادة مرشدي حماية الطفولة العاملين في وزارة التتمية الاجتماعية، كما اتجهت غالبية الدراسات السابقة إلى ضرورة توعية مرشدي حماية الطفولة بالأساليب

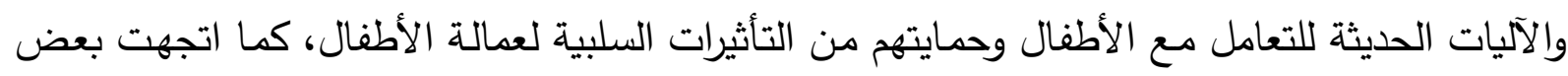


الدراسات السابقة إلى ضرورة قيام وزارة التنمية الاجتماعية بالتنسيق مع كافة المؤسسات الرسمية وغير

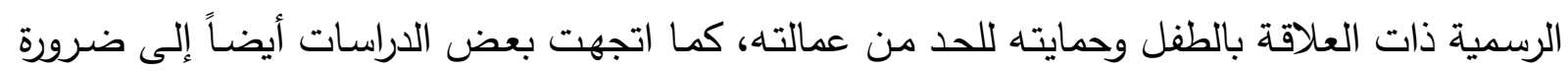
تعيين مرشدين حمايـة طفولـة في وزارة التتميـة الاجتماعية وفق معيـار الكفاءة، من حيث التخصص المناسب لهذا العمل والتفوق فيه، وقدرته على القيام بوظائفه وفق الآليات الحديثة، كما اتجهت بعض في

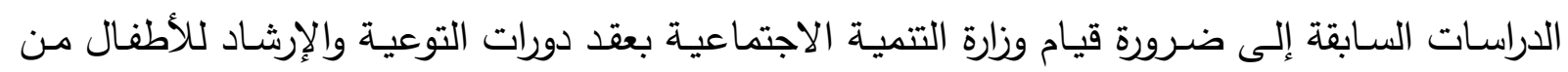
خلال الددراس ومؤسسات المجتمع المحلي، كما اتجهت بعض الدراسات السابقة إلى تخصيص جزء من أموال ميزانية وزارة التتمية الاجتماعية لدعم الأطفال المهددين بالخطر وحياتهم، وضرورة دعم دور الرعاية الاجتماعية كي يتمكنوا من حماية الأطفال وفق أفضل أساليب الرعاية الاجتماعية.

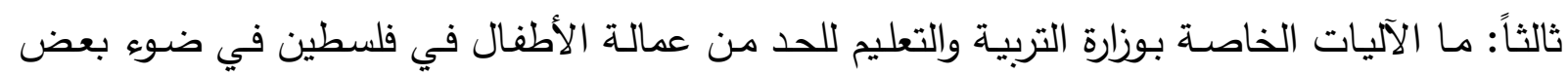

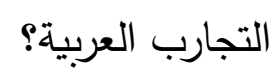
أجمعت الدراسات السابقة إلى مجانية التعليم، كما اتجهت معظم الدراسات السابقة إلى ضرورة زيادة عدد المدراس والصفوف الدراسية وتحسين البيئة المدرسية لاستيعاب الأطفال وفق ظروف ومناخ علمي وتربوي، كما اتجهت معظم الدراسـات السابقة إلى ضـرورة قيام الوزارة بوضع الحلول المناسبة لظـاهرة التسرب المدرسي والتي تعتبر من أكثر مصادر عمالة الأطفال. كما اتجهت بعض الدراسات السابقة إلى ضرورة تتفيذ برامج تعليمية للتلاميذ بالمؤسسات التربويـة لتعريفهم بحقوقهم كأطفال، وبيان الجوانب السلبية لعمالة الأطفال من خلال النشاطات الددرسية الصفية واللاصفية، كما اتجهت بعض الدراسات السابقة إلى ضرورة تعيين أخصائي اجتماعي ونفسي في كل

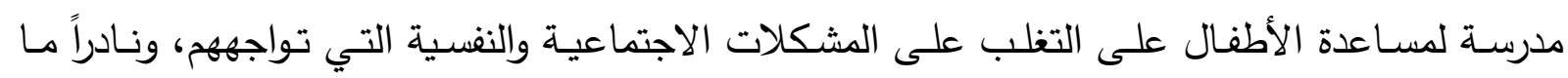
اتجهـت الدراسـات السـابقة إلى ضـرورة زيـادة الوعي للدى المدرسين والمعلمين في المدراس بالأسـاليب الحديثة للتعامل مـع الأطفال وخصوصـاً المرحلـة الابتدائية التي تتكون فيهـا شخصية الطفل، ويتأثر بالمعززات الخارجيـة والمحيطة، وذلك لأهميـة دور المدرس كممثل للدولـة فهو مسؤول عن نقل القيم والمبادئ الأساسية في المجتمع، مع مساعدة الطفل على إكسابها، فالدولة مسؤولة عن تحديد السياسة التربويـة بما يتماشى ومتطلبات المجتهع واحتياجات وتطلعاته مـع الحرص على تنفيذ الخطط والبرامج

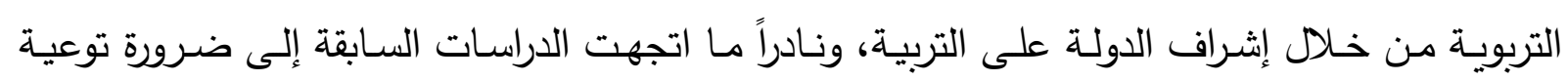
الأطفال مـن خـلال البرامج المدرسية بحقوقهم في اتفاقيـة حقوق الطفل، وقانون الطفل الفلسطيني. 
رابعاً: مـا الآليات الخاصـة بالسلطة التشريعية للحد من عمالة الأطفال في فلسطين في ضـوء بعض

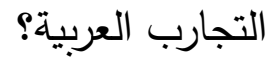

اتجهـت معظم الدراسـات السـابقة إلىى تفعيـل العهـل بالاتفاقيـات الدوليـة الخاصـة برعايـة الطفـل وخصوصاً اتفاقية حقوق الطفل لسنة 1989، كما اتجهت معظم الدراسات السابقة أيضاً إلى تفعيل العمل بالقوانين الصـادرة من الدولتة والمتعلقـة بحمايـة الطفل، كما اتجهت بعض الدراسـات السـابقة إلى ضـرورة إيجاد آليات محددة لمتابعة تتفيذ الاتفاقيات والقوانين.

كما اتجهت بعض الدراسات السابقة إلى أن تتضمن التشريعات والقوانين الوطنية كافة الأمور التي تحمي الطفل وتضمن حقوقه، كما اتجهت بعض الدراسات السابقة إلى ضرورة أن يحدد المشرع الأعمال الصعبة والخطرة التي يحظر على الأحداث العمل فيها، كما اتجهت بعض الدراسات السابقة إلى التطبيق الصارم للقوانين التي يتم بموجبها منع تشغيل الأطفال، كما اتجهت بعض الدراسات السابقة إلى ضرورة تشديد العقوبـة على أصـاب العمل المشغلين للأطفال، كما اتجهت بعض الدراسات السابقة إلى وضـع قوانين تحظر عمل الأطفال الأقل من 16 سنة، حيث يعتبر هذا العمر مناسباً لبدء الإنسان العمل من الناحية الجسدية والنفسية. ونادراً ما اتجهت الدراسات السابقة إلى ضرورة قيام السلطة التشريعية بإجراء التعديلات على القوانين الوطنية المتعلقة بالطفل بما يتناسب مع اتفاقيات حقوق الطفل لضمان حمايتهم وفق أفضل الممارسات الدولية، ونـادراً مـا اتجهت الدراسـات السـابقة إلى إعداد اللوائح والقرارات المكملة والمنفذة لأحكام قوانين العمل، والطفل في مجال حماية الأطفال وتتظيم عمل الأطفال. خامساً: ما الآليات الخاصـة بمؤسسات المجتمع المدني للحد من عمالة الأطفال في فلسطين في ضوء بعض التجارب العربية؟ أجمعـت معظم الدراسـات السـابقة إلى ضـرورة التعـاون والتنسيق بـين مؤسسـات المجتمـع المحلي (هيئات محلية، جمعيات خيريـة، أنديـة رياضية، اتحادات أهلية، نقابات ومؤسسات حقوق الإنسان) مـع الجهات الرسـمية ذات العلاقـة بحمايـة الطفل وخصوصـاً وزارة التربيـة والتعليم، و وزارة العمـل والتتميـة الاجتماعيـة، كمـا اتجهـت بعض الدراسـات السـابقة إلى ضـرورة تـولي المجتمـع المدني مسؤولية توعيـة وتثقيف هذه العائلات وإعانتها على إيجاد فرص عمل، كما اتجهت بعض الدراسات السابقة إلى ضرورة قيام مؤسسـات المجتمـع المدني وخصوصـاً الهيئات المحلية على متابعـة الأطفال ومنعهم مـن التسرب المدرسي، كما اتجهت بعض الدراسات السابقة إلى ضرورة توجيه الجمعيات الخيريـة الدعم والمساعدة في 
التغلب على عمالة الأطفال، كما اتجهت بعض الدراسات السابقة إلى ضرورة تثجيع إنثاء جمعيات غير حكومية تعنى وتهتم بمكافحة عمالة الأطفال.

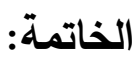

تطرقنا في هذه الدراسة إلى بناء تصور مقترح للحد من عمالة الأطفال في فلسطين، من خلال

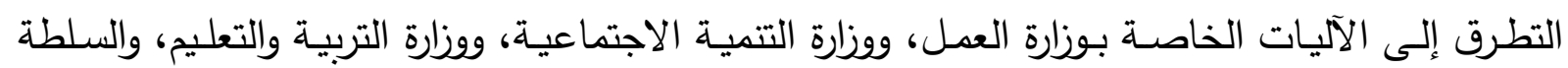
التشريعية، ومؤسسـات المجتمع، حيث تم التوصل بنـاء على ذلك إلى تصور مقترح للحد من عمالة الأطفال في المجتمع الفلسطيني، وعليه أوصت الدراسة بمجموعة من التوصيات، أبرزها: - تثكيل لجنة وطنية عليا لمكافحة عمالة الأطفال تقوم بالتتسيق مع كافة الهيئات والجهات ذات العلاقة. - تبني التصور المقترح في هذه الدراسة.

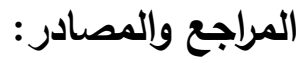 \\ أولا: المراجع العربية}

1. أبو زايد، أحمد (2010). الرضا عن العمل وعلاقته بالتوافق النفسي للأطفال العاملين في المحافظة

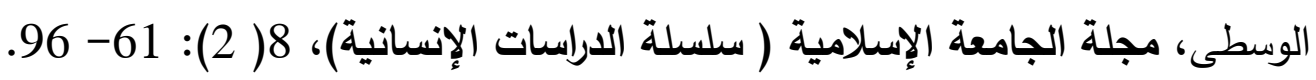
2. الزعبوط، سـمية (2016). استثـراف مستقبل عمالـة الطفـال في الأردن، مجلـة الأنـلس للعــوم الإنسانية والاجتماعية، جامعة الأندلس للعلوم والتقنية، 13(11): 129- 162.

3. الثامي، دفيد، ابو وطفه، ختام (2002) عمالة الاطفال في فلسطين دراسة تحليلية، مجلة جامعة

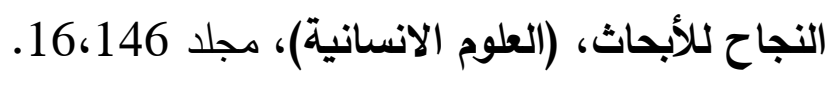

4. الطراونـة، هيا، والمعاني، محمد (2018). تقييم السياسات الاجتماعية لعمالة الأطفال في الأردن.

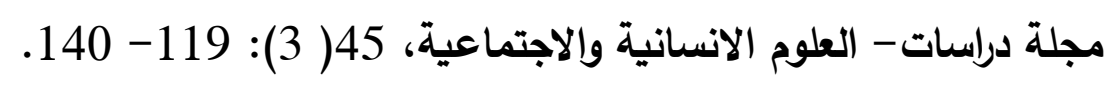

5. الطرشـاني، الدوكالي (2016). البعد الاجتمـاعي والاقتصـادي لعمالـة الأطفال في الهجتمع الليبي:

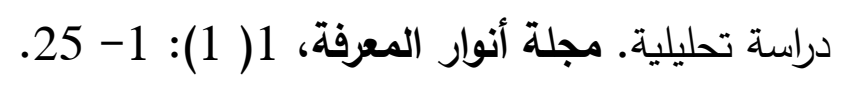

6. الطواشـي، وسـام( 2015). عمالـة الأطفال في قطاع غزة وأثرهـا على المستقبل المهني للأجيال القادمة، رسالة ماجستير، الجامعة الإسلامية: غزة. 7. العيسوي، حمادة السيد( 2017). ظاهرة عمالة الأطفال في مصر : مؤشرات ودلالات. مجلة الخدمة الاستة الاجتماعيـــــة، الجمعيـــة الدصــرية للأخصـــائيين الاجتمـــاعيين، 58( 10): 104- 123. 
8. الكريم، راشد (2019)، مطارحة في البحث العلمي حول التصور المقترح، مقال منشور على الموقع الاككتروني https://www.al-jazirah.com/2019/20191019/cm13.htm تاريخ الدخول

$$
2020 / 9 / 2
$$

9. بشير ، اليمان، والناصر ، بوديزة( 2015). عمالة الأطفال وعلاقتها بالتسرب المدرسي: دراسة ميدانية على عينة من الأطفال بدائرة الطيبات- ورقلة، رسـالة ماجستير، جامعة قاصدي مرباح- ورقلة:

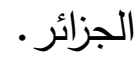

10. بن زعزع، لمياء، واخرون ( 2019). عمالة الأطفال وانعكاساتها على المجتمع الجزائري، مجلـة

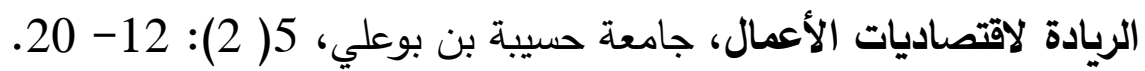
11. بن ناصر ، فرحات، وبو جمعة، حريزي( 2017). ظاهرة عمالة الأطفال في الجزائر من منظور نفسي اجتماعي، مجلة جيل العلوم الإنسانية والاجتماعية، مركز جيل البحث العلمي، ع( 27): $.169-159$

12. جاد، جيهان( 2019). عمالة الأطفال في إفريقيا جريمة إنسانية وتتموية، قراءات إفريقية، المنتدى

$$
\text { الإسلامي، ع( 41): 70- } 81 .
$$

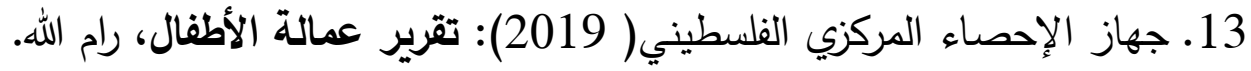
14. رزق الله، سلمى( 2015). واقع عمالة الأطفال في الجزائر : دراسة ميدانية لعينة من الأطفال بولاية

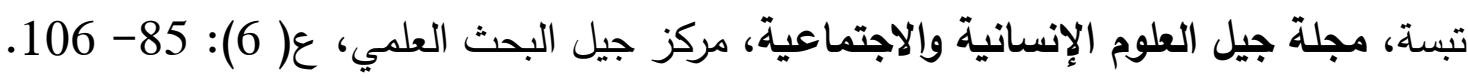

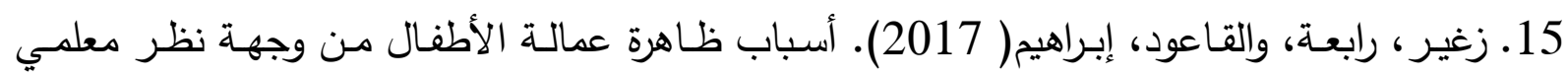

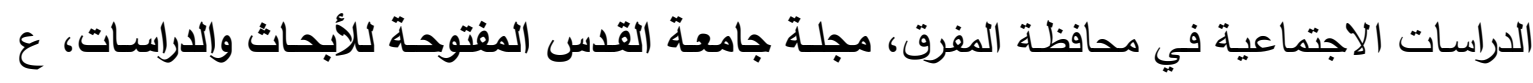

$$
.226-212:(41)
$$

16. زوزو، شيد، وبن عيسى، رابح( 2016). عمالة الأطفال في الجزائر : الأسباب الانكاسات والحلول،

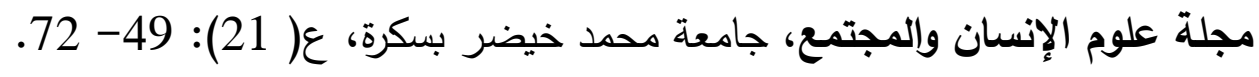
17. زيتوني، عائشة بية( 2017). عوامل عمالة الأطفال في الثارع الجزائري: دراسة حالة ببعض أحياء مدينة عنابة، مجلة العلوم الإنسانية والاجتماعية، ع( 31): 497- 506. 18. عبد الله، تيسير ؛ واخرون ( 2019). عماــة الأطفـال وعلاقتهـا بالتسـرب فـي مــارس القـس الثريف، وزارة التربية والتعليم الفلسطيني، رام الله. 
19. قحطان، محمد علي( 2007). عمالة الأطفال في اليمن: حالة مدينة الحديدة، دراسات مستقبلية،

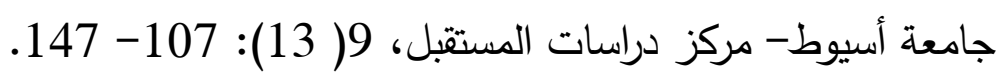

20. كاظم، سميرة( 2011). عمالـة الأطفال في العراق: الأسباب والحلول، مجلـة البحـوث التربويـة

$$
\text { والنفسية، ع( 30): 150- } 192 .
$$

21. محافظـة، سـامح( 2011). عمل الطفـال: دراسـة في العوامل الاجتماعيـة والاقتصـادية والتعليميـة لعمالة الأطفال في الأردن، مجلة جامعة الزرقاء للبحوث والدراسات الإنسانية، 11( 2): 37- 51. 22. مرعي، طارق( 2019). الآثار السلبية المترتبة على عمالة الأطفال: دراسة لوضع برنامج مقترح من منظور الممارسة العامة للخدمة الاجتماعية لمواجهتها، مجلـة الخدمـة الاجتماعيـة، 2( 61): $.207-149$

23. مصري، محمود (2012). حقوق الطفل في المنطقة العربية الواقع والمأمول، دمثق: دار نينوى لـلدراسات والنشر والتوزيع.

24. موسى، أحمد( 2009). أطفال الشوارع/ المثكلة وطرق العلاج، المنصورة: المكتبة العصرية للنشر والتوزيع.

25. ياقو، منى، وعلي، صفاء( 2018). الحماية القانونية من عمالة الأطفال: دراسة مقارنة، مجلة كلية

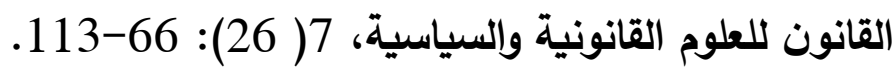

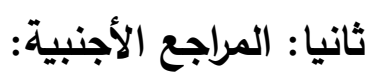

\section{References}

1. Amon, J.; Buchanan, J.; Cohen, J. \& Kippenberg, J.( 2012). Child Labor and Environmental Health: Government Obligations and Human Rights, International Journal of Pediatrics, 2012: 1-8. doi:10.1155/2012/938306

2. Putnick, D. \& Bornstein, M.( 2015). Is Child Labor a Barrier to School Enrollment in Low- and Middle-Income Countries? International Journal of Educational Development. 2015 March 1; 41: 112-120. doi:10.1016/j.ijedudev.2015.02.001.

3. Edmonds, E. \& Pavcnik, N.( 2005). Child Labor in the Global Economy, Journal of Economic Perspectives, 19( 1). 99-220.

4. Habib, R.; Ziadee, M.; Younes, E.\& Harastani, H.( 2020). Syrian refugee child workers: Gender differences in ergonomic exposures and 
تصور متترح للدد من عمالة الأطفال في فلسطين ... رحاب السعدي وعصام الأطرش

musculoskeletal health, Applied Ergonomics, 83: 1-7. https://doi.org/10.1016/j.apergo.2019.102983

5. Khakshour,A.; Abbasi,M.; Seyedi.S. \& Saeidi, M.( 2015). Child Labor Facts in the Worldwide: A Review Article, International Journal of Pediatrics, 3( 1-2): 475-481.

6. Khatab, K.; Raheem, M.; Sartorius, B. \& Ismail, M.( 2019). Prevalence and risk factors for child labour and violence against children in Egypt using Bayesian geospatial modelling with multiple imputation, PLoS ONE, 14(5): e0212715. https:// doi.org/10.1371/journal.pone.0212715

7. Mansour, A.; Al-Gamal, EK.; Sultan, M.; Matrouk, R.\& Al Nawaisieh, M.(2013). Health status of working children in Jordan: Comparison between working and non-working children at School and industrial sities, Open Journal of Nursing, 3(2013), 55-62. doi:10.4236/ojn.2013.31007

8. Roggero, P.; Mangiaterra, V.; Bustreo, F.\& Rosati, F. (2018). The health Impact of Child Labor in Developing Countries: Evidence from CrossCountry Data, American Journal of Public Health, 97, 271-275.

9. Shendell, D.G., Noomnual, S., Chishti, S., Sorensen Allacci, M., Madrigano, J.( 2016). Exposures resulting in safety and health concerns for child laborers in less developed countries. Journal of Environmental and Public Health, 2016: 1-10. DOI: 10.1155/2016/3985498

10. Webbink, E., Smits, J. \& Jong, E.( 2013). Household and Context Determinants of Child Labor in 221 Districts of 18 Developing Countries, Social Indicators Research, (2013) 110:819-836. DOI 10.1007/s11205-011-9960-0

11. Zafar, Z.; Sarwar, I. \& Haider, S.( 2016). Socio-Economic and Political Causes of Child Labor: The Case of Pakistan, Global Political Review (GPR), 1( 1), 32 - 43. DOI: 10.31703/gpr.2016(I-I).04 